\title{
Influence of the Passive Stabilization of the Trunk and Upper Limb on Selected Parameters of the Hand Motor Coordination, Grip Strength and Muscle Tension, in Post-Stroke Patients
}

\author{
Anna Olczak ${ }^{1,2, *}$ and Aleksandra Truszczyńska-Baszak ${ }^{3}$ (D) \\ 1 Rehabilitation Clinic, Military Institute of Medicine, 128 Szaserów Street, 04-141 Warsaw, Poland \\ 2 Social Academy of Science, 11 Łucka Street, 00-842 Warsaw, Poland \\ 3 Faculty of Rehabilitation, Józef Piłsudski University of Physical Education in Warsaw, 00-968 Warsaw, Poland; \\ aleksandra.truszczynska@awf.edu.pl \\ * Correspondence: anna.olczak@wim.mil.pl
}

Citation: Olczak, A.;

Truszczyńska-Baszak, A. Influence of the Passive Stabilization of the Trunk and Upper Limb on Selected Parameters of the Hand Motor Coordination, Grip Strength and Muscle Tension, in Post-Stroke Patients. J. Clin. Med. 2021, 10, 2402. https://doi.org/10.3390/jcm10112402

Academic Editors: Tissa Wijeratne, Hugues Chabriat and Lindsay A. Farrer

Received: 23 March 2021

Accepted: 27 May 2021

Published: 29 May 2021

Publisher's Note: MDPI stays neutral with regard to jurisdictional claims in published maps and institutional affiliations.

Copyright: (c) 2021 by the authors. Licensee MDPI, Basel, Switzerland. This article is an open access article distributed under the terms and conditions of the Creative Commons Attribution (CC BY) license (https:// creativecommons.org/licenses/by/ $4.0 /)$.

\begin{abstract}
Objective: Assessment of the influence of a stable trunk and the affected upper limb (dominant or non-dominant) on the parameters of the wrist and hand motor coordination, grip strength and muscle tension in patients in the subacute post-stroke stage compared to healthy subjects. Design: An observational study. Setting: Stroke Rehabilitation Department. Subjects: Thirty-four subjects after ischemic cerebral stroke and control group-32 subjects without neurological deficits, age and body mass/ height matched were included. Main measures: The tone of the multifidus, transverse abdominal and supraspinatus muscles were assessed by Luna EMG device. A HandTutor device were used to measure motor coordination parameters (e.g., range of movement, frequency of movement), and a manual dynamometer for measuring the strength of a hand grip. Subjects were examined in two positions: sitting without back support (non-stabilized) and lying with stabilization of the trunk and the upper limb. Results: Passive stabilization of the trunk and the upper extremity caused a significant improvement in motor coordination of the fingers $(p<0.001)$ and the wrist $(p<0.001)$ in patients after stroke. Improved motor coordination of the upper extremity was associated with an increased tone of the supraspinatus muscle. Conclusions: Passive stabilization of the trunk and the upper limb improved the hand and wrist coordination in patients following a stroke. Placing patients in a supine position with the stability of the affected upper limb during rehabilitation exercises may help them to access latent movement patterns lost due to neurological impairment after a stroke.
\end{abstract}

Keywords: cerebral stroke; hand rehabilitation; core stability; muscle tone; motor coordination

\section{Introduction}

Up to $50 \%$ of patients report impaired upper limb and hand function following a stroke [1-3]. Unfortunately, functional restoration of the upper extremity requires a long-lasting physiotherapy and often fails to meet patients' expectations [4,5]. Thus, it is important to develop new therapies to improve the motor function of the upper extremity in stroke patients [6-11].

The stabilization of the human body is the basis for maintaining balance and makes it possible to perform selective, coordinated movements with parts of the body [12-17]. There are several elements to the body's stability: central stabilization, which concerns the proper tension and work of the deep muscles of the trunk, and a stable trunk [16-18]. According to Bobath's concept, a stable trunk is a counterbalance to the movements of all limbs $[19,20]$. It is very important that the trunk is stable and mobile at the same time, because only then can any selective movement be made $[15,19,21]$. In addition to arm and hand motor function deficits, trunk movement coordination disorders have been observed in patients with stroke [22]. In particular, movement of the lower limb is associated with contraction 
of the abdominal muscles, which stabilize the spine [23]. Stabilization of the human body is essential for maintaining balance and allows coordinated movements of body parts, including the human radio-carpal joint and palm [24]. For example, a previous study showed that the position of the forearm was particularly important for achieving higher grip strength: better parameters were noted in the transverse position and the lateral plane compared to the plane consistent with the body axis and horizontal position [25]. Similarly, Okunribidi et al. found that stabilization of the forearm was particularly important for achieving higher grip strength in healthy subjects [25]. Stabilization was also key for the restoration of the correct movement pattern and for regaining function of the hand in patients with impaired motor coordination [26,27]. Similarly, passive stabilization of the trunk core may also assist in improving hand motor function following a stroke. Precise hand movements also rely on the proper functioning and position of the shoulder blade, and stroke patients often show a weakness of the shoulder (scapular) stabilizers [28,29]. The supraspinatus muscle of the shoulder plays an important role in the abduction, flexion and external rotation of the arm. Brunnstrom (1970) in her book recalls the Souque's phenomenon, discovered by him in 1916 and consisting in that elevation of the affected arm frequently caused the paralyzed finger to extend [30]. A different study has shown that elbow joint control is dependent on shoulder abduction and the strength of shoulder abduction affects the elbow-flexion torque and, with that, the reaching range of motion (work area) in patients after stroke [31]. Nijland, et.al. in 2010 presented a paper on the basis of which they determined functional recovery of the hemiplegic arm at 6 months can be predicted early in a hospital stroke unit within $72 \mathrm{~h}$ after stroke onset, using two simple tests, finger extension and shoulder abduction [32]. Tanzarella et al. (2020), presented a non-invasive command study structure for draining up to 14 external and internal hand muscles. They extended previous research (limited to a few muscles) on a common synaptic signal in pools of motor neurons in a large number of muscles. The results showed that the component of the set of decoded spine trains of motor neurons was positively correlated with the force for all subjects and tasks. By grouping pools of motor neurons from external or internal muscles, a score correlated with strength was also obtained. These observations show low-dimensional control of motor neurons in many muscles, which can be used to extract control signals in nerve coupling, which can help in hand rehabilitation, e.g., control of the exoskeleton of the hand in patients after stroke, among others [33]. Modern devices used for therapy often use the principle of biofeedback. Biofeedback engages the brain to work, as a result of which the brain begins to learn, finding new possibilities to control, for example, muscles deprived of central control of movements [34,35]. The results of the study conducted by Delph et al. (2013) showed that by far the most popular type of device among those analyzed in the study was a device that used a pneumatic actuator to direct the flexion/extension of the finger [36]. To improve the function of the hand, transcranial magnetic stimulation with the use of non-invasive devices is also used. A randomized, double-blind study showed an increase in the physiological activity of the brain in the areas near the stroke $[37,38]$. Thanks to this, it is possible to improve many functions and motor activities, such as hand pressure and movements of the upper limbs as well walking speed [39]. Nevertheless, post-stroke patients have limitations in the movement of the distal upper limb. Especially in extending the wrist and fingers, due to the lack of, decreased or increased tension of a spastic nature.

So far, the influence of trunk and shoulder stabilization on the parameters of wrist and hand movements in patients after stroke has not been described.

The aim of the study was to evaluate the influence of the stable position of the trunk and upper limb on the parameters of hand and wrist movement coordination, grip strength and muscle tension in subacute post-stroke patients compared to healthy subjects. The aim of the study was also to evaluate the parameters of the affected upper limb depending on whether the examined limb was dominant or non-dominant. 


\section{Materials and Methods}

\subsection{Study Design}

This is an observational study. Measurements made in two different positions of the trunk and affected upper limb. It has been checked how the intervention (effectiveness of stabilization) influence on a change in parameters. The passive and active range of motion, the maximum range of movement (ROM) and the frequency of movement at the wrist and fingers, as well as the grip force and the tension of the muscles deeply stabilizing the trunk and shoulder joint (dependent variables) were assessed among post-stroke patients in the sitting (non-stabilized) and supine (stabilized) position (independent variables). A group of healthy people was examined to assess whether neurological deficits in people after a stroke might affect the results of motor coordination and grip strength.

\subsection{Ethics}

The study was carried out in the Teaching Department of Rehabilitation of the Military Medical Institute (MMI) in Warsaw, Poland. It was approved by and carried out in accordance with the recommendations of the Ethical Committee of the Military Medical Institute (approval number 6/MMI/2020). Prior to inclusion, all subjects were informed about the purpose of the study. Written informed consent was obtained from all subjects in accordance with the tenets of the Declaration of Helsinki.

\subsection{Subjects}

In total 100 people were examined before including. 34 people (27 stroke patients and 7 healthy) were excluded because of their functional condition. Finally, 66 males and females were prospectively recruited from among patients of the Teaching Department and of the Physical Medicine Department of the MMI. Participation in this study was voluntary. The flow of participants through each stage of the study is shown below (Figure 1).

In this case, 34 subjects after ischemic cerebral stroke, (aged 44-83 years; mean, $64.1 \pm 9.2$ years); biometric data in Table 1 . Study group were in the subacute (5-7 weeks past stroke) of the disease, with stable trunk (the Trunk Control Test 74-100 points), subjects were in a functional state allowing movements of the upper extremity (FMA-UE 43-49 motor function points); tension of forearm and hand muscles measured with Modified Ashworth Scale (MAS 1/1+) [40-42]. The clinical evaluation of patients after a stroke was performed by the physician admitting the patient to the clinic on the day of admission.

Table 1. Biometric data of study population and clinical control group.

\begin{tabular}{lrrrr}
\hline Group & Age & \multicolumn{1}{c}{ Height } & \multicolumn{1}{c}{ Body Mass } & \multicolumn{1}{c}{ BMI } \\
\hline Stroke & $64.1 \pm 9.2$ & $167.7 \pm 7.5$ & $76.4 \pm 9.4$ & $27.16 \pm 2.8$ \\
Control & $58.6 \pm 11.9$ & $170.78 \pm 8.8$ & $72.50 \pm 11.0$ & $24.8 \pm 2.7$ \\
Wilcoxon & 384.50 & 431.50 & 449.00 & 297.00 \\
$Z$ & -2.05 & -1.45 & -1.22 & -3.17 \\
$p$ & 0.040 & 0.148 & 0.222 & 0.002 \\
effect size & 0.25 & 0.18 & 0.15 & 0.39 \\
\hline
\end{tabular}




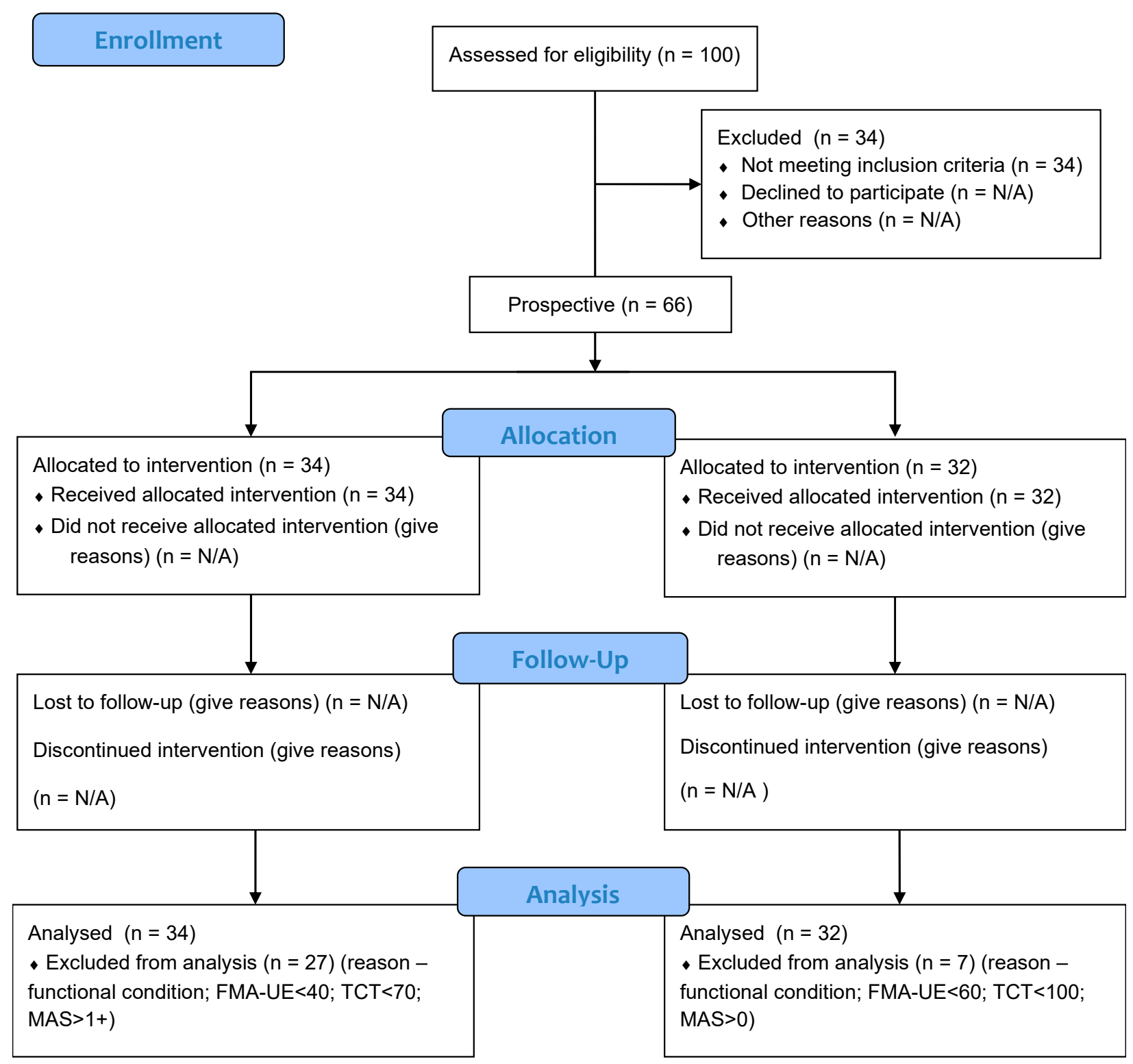

Figure 1. Flow of participants through each stage of the study.

The control group comprised 32 subjects neurologically healthy patients (aged 35-74 years; mean, $58.6 \pm 11.9$ years); biometric data in Table 1 . The control group was highly functional with stable trunk (the Trunk Control Test 100 points), (FMA-UE 66 motor function points); tension of forearm and hand muscles measured with Modified Ashworth Scale (MAS 0) [40-42].

The characteristics of the subjects are shown in Table 1.

Criteria for stroke group inclusion (1) patients with ischemic stroke; (2) patients with hemiparesis after 5 to 7 week after stroke; (3) subjects with stable trunk (the Trunk Control Test 70-100 points); (4) subjects who were in a functional state allowing movements of the upper extremity (FMA-UE 40-66 motor function points); (5) muscle tension (MAS $0-1+)$; (6) no severe deficits in communication, memory or understanding what can impede proper measurement performance; (7) at least 35 years of age; (8) maximum 83 years of age. 
Criteria for stroke group exclusion: (1) stroke up to five weeks after the episode, (2) epilepsy, (3) lack of trunk stability, (4) no wrist and hand movement, (5) high or very low blood pressure, dizziness, malaise, (6) local infection of skin in the hand region.

Criteria for control group inclusion: (1) the control group consisted of subjects free from the upper extremity motor coordination disorders (FMA-UE 60-66 motor function points); subjects with stable trunk (TCT 100 points); correct muscle tension (MAS 0); (2) at least 35 years of age; (3) maximum 83 years of age.

Criteria for control group exclusion: (1) a history of neurologic or musculoskeletal disorders such as carpal tunnel syndrome, tendonitis, stroke, head injury or other conditions that could affect their ability to active movement and grip hand; (2) back pain; (3) no severe deficits in communication, memory or understanding what can impede proper measurement performance; (4) high or very low blood pressure, dizziness, malaise, (5) local infection of skin in the hand region.

\subsection{Apparatus}

The research was carried out according to the protocol no 3/KRN/2019, registered in Clinical Trial Registration.

A Luna EMG (a rehabilitation-diagnostic robot developed by EGZOTech, Gliwice, Poland) was used to measure muscle tension (accuracy of measurement $[-1-+1 \mathrm{~V}+/-1 \mathrm{mV}]$ ). A manual electronic dynamometer (EH 101; Camry, Shiqi, China) was used for grip strength measurement (error of measurement $0.5[\mathrm{~kg} / \mathrm{lb}]$ ). A Hand Tutor device composed of a safe and comfortable glove (with sensitive electro optical sensors evaluating position, speed wrist and finger movement; power supply: voltage: 5 [V] DC, rated current input: $300[\mathrm{~mA}])$, and the Medi Tutor TM software. A Hand Tutor was used to measure the kinematic parameters like: range of passive and active movement, deficits of movement (sensitivity: 0.05 [mm] of wrist and fingers Ext./Flex) as well as the speed/frequency of movement (motion capture speed: up to $1[\mathrm{~m} / \mathrm{s}]$ ). The system (MediTouch, Israel) is used by many leading physical and occupational therapy centers worldwide and has CE and FDA certification [43]. The Hand Tutor glove was worn on the hand of the directly affected side in stroke patients and on the dominant extremity control group. Surface electrodes (single-use 55' and '40 mm; EMG Electrodes; Sorimex, Poland) were affixed to the subject's body according to the SENIAM (Surface ElectroMyoGraphy for the Non-Invasive Assessment of Muscles) procedure on the transverse abdominal, multifidus and supraspinal muscles (on the side directly affected in stroke patients). Before each exercise, the subject was instructed on how the exercise should be done.

\subsection{Measurements}

The examination consisted of two motor tasks, carried out in two different starting positions: sitting and lying down (supine). During the first examination, the subject sat on the therapeutic table (without back support), feet resting on the floor. The upper limb was to be examined in adduction of the humeral joint, with the elbow bent in the intermediate position between pronation and supination of the forearm. The wrist and the hand were free (no stabilization) but patients were asked to keep the wrist and hand in the extension of the forearm (as shown in Figure 2). 


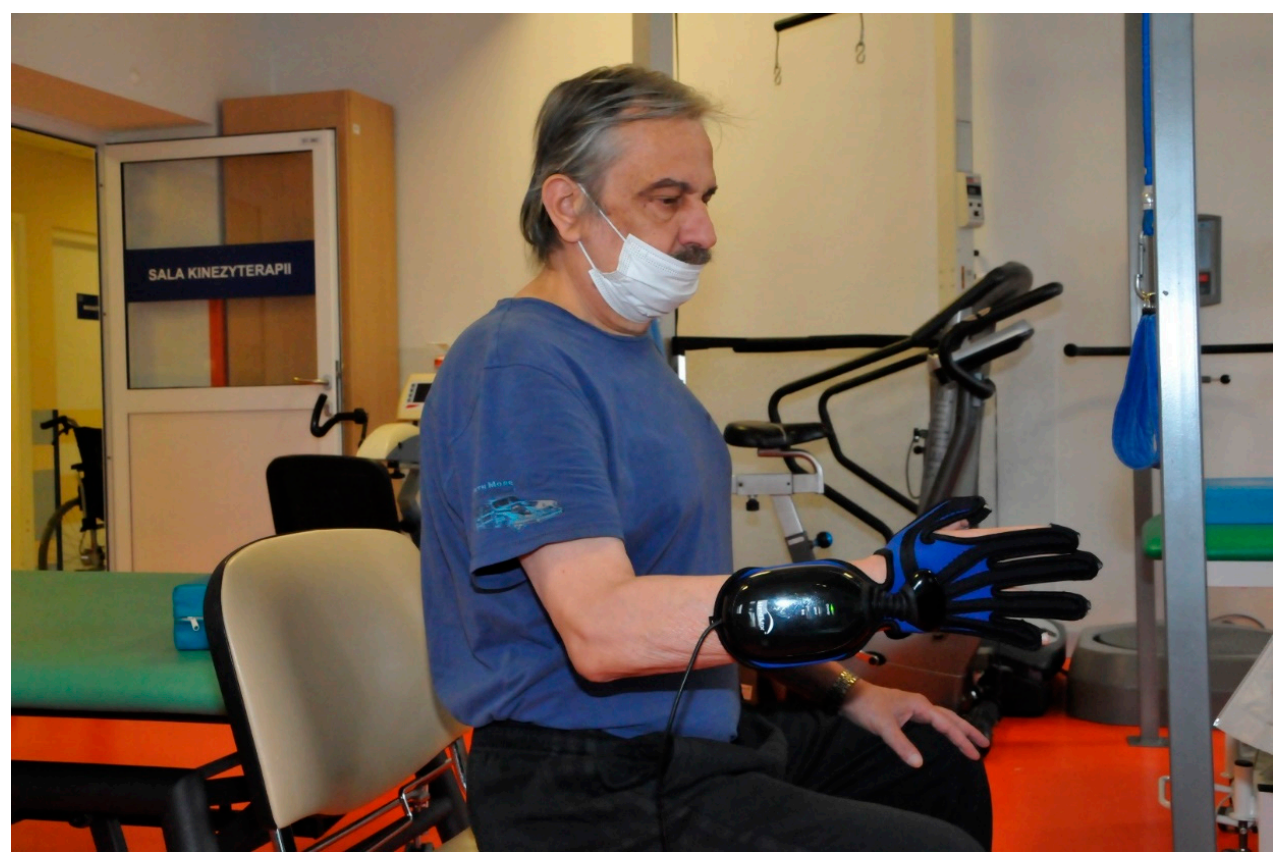

Figure 2. Sitting without back support (unstable position).

The described position of the upper extremity is typically impossible to achieve in stroke patients without stabilization. Instead, features of flexion synergy (abduction in the humeral joint) were observed.

In the supine position, the upper limb was stabilized at the subject's body (adduction in the humeral joint, elbow flexion in the intermediate position between pronation and supination of the forearm, with free wrist and the hand). In this position, patients were also asked to keep the wrist and hand in the extension of the forearm during each measurement (movement and grip strength) (Figure 3).

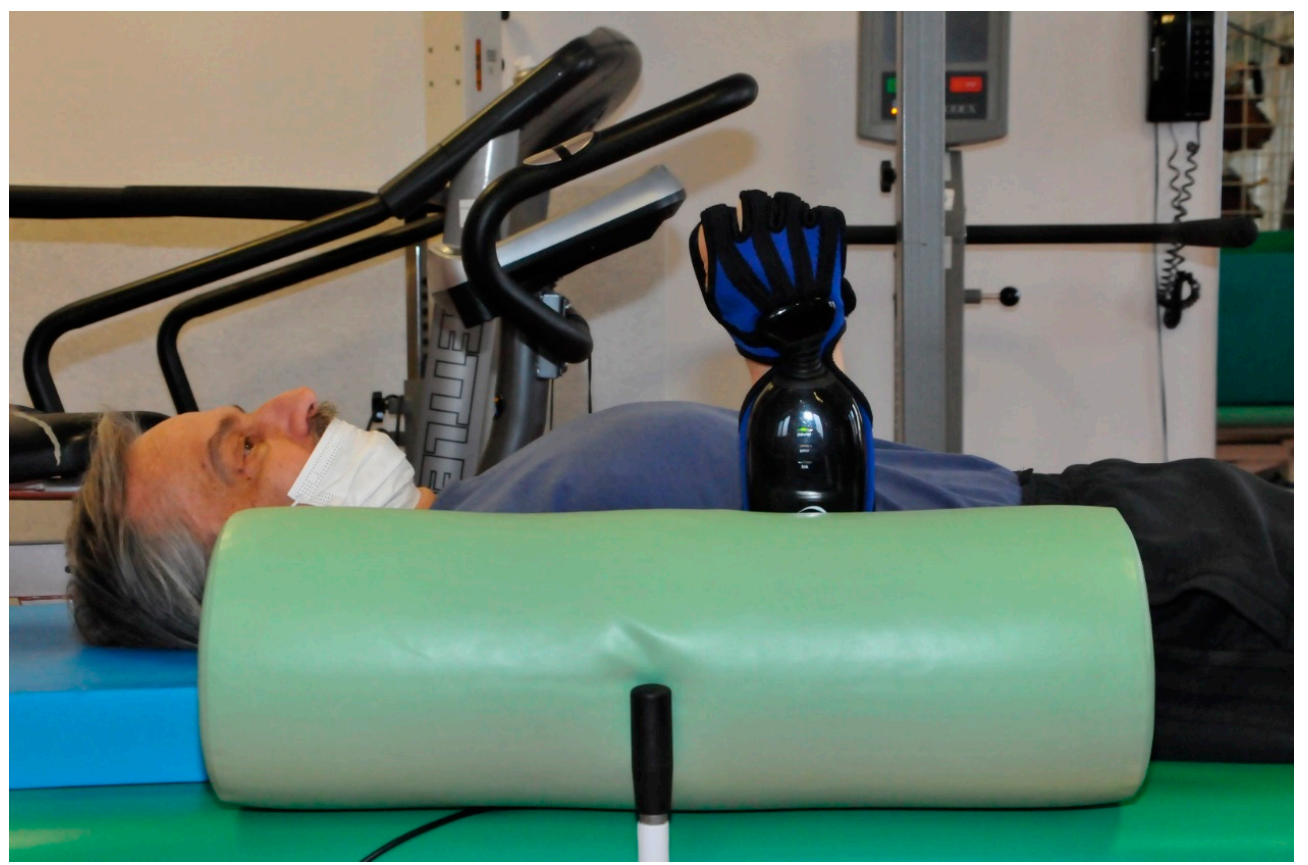

Figure 3. Passive stabilization of the trunk and upper limb (stable position). 
First, the range of passive in the radial-carpal joint (flexion and extension) and fingers (global flexion and extension) was measured in each position (sitting or supine) using the Hand Tutor device. The device also measured flexion/extension deficit refers to the difference between passive and active ROM.

Then the subject made active movements in the same order. Finally, the subject was asked to make moves as quickly and in as full a range as possible. The measurement of grip strength with a dynamometer was performed in both positions (sitting or supine) after the range of motion and speed/frequency tests. The reaction of the examined multifidus, transverse abdominal and supraspinatus muscles (tension values reported in microvolts $[\mu \mathrm{V}])$ was also assessed during each of the exercise tasks using the surface electrodes (i.e., during movement of the wrist and during movement of the fingers).

\subsection{Sample Size Calculation}

The sample size was estimated using the $G *$ Power 3.1.9.4 program. Assuming the following parameters: Effect size $\mathrm{d}=0.9, \alpha=0.05$; Power $=0.95$ for the Wilcoxon-MannWhitney test, the required sample size was 58 ( 29 people per group).

\subsection{Statistical Analysis}

All statistical analyses were performed using the IBM SPSS Statistics suite, version 25 (IBM Corporation, Armonk, NY, USA). All data was analyzed using basic descriptive statistics. The distribution normality of the data was determined. The consistency with a normal distribution was verified with the Shapiro-Wilk test. Comparisons between two groups were performed using the $U$ Mann-Whitney test. The Wilcoxon signed-rank test was used to compare measurements made in the non-stabilized and stabilized positions. A $p$-value of $<0.05$ was considered statistically significant.

\section{Results}

First, the effect of stabilization of the trunk and upper limb on the motor coordination of the hand and wrist was assessed in stroke patients (Table 2). Stabilization had no effect on the passive and active movement of the wrist and fingers or the deficits of extension and flexion. However, the frequency of movement of fingers 5, 4, 3 and 2 was higher in a stabilized position. Meanwhile, the maximum range of motion (ROM) of fingers 3 and 4 was higher in the non-stabilized position.

Table 2. Motor coordination of the hand and wrist in stroke patients with and without stabilization of the trunk and upper limb.

\begin{tabular}{|c|c|c|c|c|c|}
\hline & \multicolumn{2}{|c|}{ No Stabilization } & \multicolumn{2}{|c|}{ Stabilization } & \multirow{2}{*}{$p^{*}$} \\
\hline & $\mathbf{M}$ & SD & $\mathbf{M}$ & SD & \\
\hline Range of active movement of the wrist, $\mathrm{mm}$ & 17.91 & 6.17 & 18.74 & 6.28 & 0.374 \\
\hline Range of passive movement of the wrist, $\mathrm{mm}$ & 25.35 & 3.76 & 25.38 & 4.48 & 0.922 \\
\hline 5th finger active movement, $\mathrm{mm}$ & 19.47 & 9.06 & 17.56 & 8.12 & 0.069 \\
\hline 5th finger passive movement, $\mathrm{mm}$ & 23.41 & 8.99 & 21.26 & 7.73 & 0.050 \\
\hline 4 th finger active movement, $\mathrm{mm}$ & 23.03 & 7.38 & 21.56 & 7.80 & 0.062 \\
\hline 4th finger passive movement, $\mathrm{mm}$ & 27.62 & 6.72 & 25.35 & 6.79 & 0.069 \\
\hline 3rd finger active movement, $\mathrm{mm}$ & 22.94 & 6.05 & 22.47 & 5.85 & 0.253 \\
\hline 3rd finger passive movement, $\mathrm{mm}$ & 27.12 & 5.61 & 26.15 & 5.54 & 0.536 \\
\hline 2nd finger active movement, $\mathrm{mm}$ & 20.65 & 5.88 & 20.29 & 5.75 & 0.528 \\
\hline 2nd finger passive movement, $\mathrm{mm}$ & 27.00 & 5.50 & 25.09 & 4.44 & 0.085 \\
\hline 1st finger active movement, $\mathrm{mm}$ & 9.18 & 5.61 & 8.44 & 4.86 & 0.573 \\
\hline 1st finger passive movement, $\mathrm{mm}$ & 12.68 & 5.81 & 12.97 & 5.73 & 0.893 \\
\hline
\end{tabular}


Table 2. Cont.

\begin{tabular}{|c|c|c|c|c|c|}
\hline & \multicolumn{2}{|c|}{ No Stabilization } & \multicolumn{2}{|c|}{ Stabilization } & \multirow{2}{*}{$p^{*}$} \\
\hline & $\mathbf{M}$ & SD & $\mathbf{M}$ & SD & \\
\hline Wrist extension deficit, $\mathrm{mm}$ & 4.21 & 3.72 & 3.76 & 3.55 & 0.250 \\
\hline Wrist flexion deficit, mm & 3.24 & 2.68 & 2.88 & 3.07 & 0.281 \\
\hline 5th finger extension deficit, $\mathrm{mm}$ & 3.03 & 2.68 & 2.88 & 2.87 & 0.521 \\
\hline 5th finger flexion deficit, $\mathrm{mm}$ & 0.91 & 1.99 & 0.82 & 1.57 & 0.932 \\
\hline 4thfinger extension deficit, $\mathrm{mm}$ & 2.82 & 2.81 & 2.06 & 1.84 & 0.205 \\
\hline 4th finger flexion deficit, $\mathrm{mm}$ & 1.76 & 3.90 & 1.74 & 2.43 & 0.483 \\
\hline 3rd finger extension deficit, $\mathrm{mm}$ & 2.59 & 3.33 & 1.82 & 1.95 & 0.247 \\
\hline 3rd finger flexion deficit, mm & 1.59 & 3.15 & 1.85 & 2.45 & 0.433 \\
\hline 2nd finger extension deficit, $\mathrm{mm}$ & 3.65 & 4.46 & 1.94 & 1.91 & 0.061 \\
\hline 2nd finger flexion deficit, $\mathrm{mm}$ & 2.71 & 3.47 & 2.85 & 2.89 & 0.844 \\
\hline 1st finger extension deficit, $\mathrm{mm}$ & 1.26 & 1.69 & 1.21 & 1.18 & 0.889 \\
\hline 1st finger flexion deficit, $\mathrm{mm}$ & 2.24 & 3.47 & 3.32 & 4.00 & 0.239 \\
\hline Frequency of wrist movement (flexion to extension), cycles ${ }^{\#} / \mathrm{s}$ & 1.15 & 0.71 & 1.21 & 0.86 & 0.698 \\
\hline Wrist maximum ROM, mm & 19.73 & 10.73 & 19.94 & 9.36 & 0.153 \\
\hline Frequency of 5th finger movement (flexion to extension), cycles \#/s & 1.55 & 0.96 & 1.67 & 0.94 & 0.016 \\
\hline 5th finger maximum $\mathrm{ROM}, \mathrm{mm}$ & 18.05 & 8.50 & 17.39 & 10.78 & 0.124 \\
\hline Frequency of 4 th finger movement (flexion to extension), cycles $\# / \mathrm{s}$ & 1.55 & 0.96 & 1.69 & 0.96 & 0.011 \\
\hline 4th finger maximum $\mathrm{ROM}, \mathrm{mm}$ & 22.70 & 8.04 & 20.56 & 7.74 & 0.018 \\
\hline Frequency of 3rd finger movement (from flexion to extension), cycles \#/s & 1.53 & 0.98 & 1.68 & 0.96 & 0.007 \\
\hline 3rd finger maximum $\mathrm{ROM}, \mathrm{mm}$ & 22.00 & 5.82 & 20.41 & 6.02 & 0.027 \\
\hline Frequency of 2nd finger movement (flexion to extension), cycles \#/s & 1.54 & 0.98 & 1.69 & 0.96 & 0.008 \\
\hline 2nd finger maximum ROM, $\mathrm{mm}$ & 18.64 & 6.01 & 18.01 & 5.94 & 0.478 \\
\hline Frequency of the 1st finger movement (flexion to extension), cycles $\# / \mathrm{s}$ & 1.17 & 0.95 & 1.19 & 1.04 & 0.453 \\
\hline 1st finger maximum ROM, mm & 9.30 & 4.78 & 8.52 & 4.24 & 0.745 \\
\hline Grip strength, kg & 18.32 & 14.26 & 19.13 & 14.22 & 0.086 \\
\hline
\end{tabular}

Legend: $\mathrm{M}-$ mean; ROM—range of motion; $\mathrm{SD} —$ standard deviation; ${ }^{*}$ Wilcoxon test; ${ }^{*}$ one cycle $=$ the movement from flexion to contraction. Notes: Passive and active ROM is a sum of all the finger flexion or extension angles (i.e., at the MCP, PIP and DIP joints); the extension deficit refers to the difference between passive and active ROM.

Next, the effect of stabilization of the trunk and upper limb on the movement of the hand and wrist in neurologically healthy subjects was assessed (Table 3). Active and passive movement of finger 5 and the wrist extension deficit were higher in the seated, non-stabilized position. Meanwhile, a higher maximum range of wrist movement was observed in the supine position with stabilization of the upper limb.

Table 3. Motor coordination of the hand and wrist in neurologically healthy subjects with and without stabilization of the trunk and upper limb.

\begin{tabular}{|c|c|c|c|c|c|}
\hline & \multicolumn{2}{|c|}{ No Stabilization } & \multicolumn{2}{|c|}{ Stabilization } & \multirow{2}{*}{$p^{*}$} \\
\hline & $\mathbf{M}$ & SD & $\mathbf{M}$ & SD & \\
\hline Range of active movement of the wrist, $\mathrm{mm}$ & 21.78 & 4.76 & 22.34 & 4.92 & 0.232 \\
\hline Range of passive movement of the wrist, $\mathrm{mm}$ & 26.63 & 4.02 & 26.16 & 4.07 & 0.304 \\
\hline 5th finger active movement, $\mathrm{mm}$ & 18.75 & 5.86 & 17.50 & 5.86 & 0.011 \\
\hline 5th finger passive movement, $\mathrm{mm}$ & 20.09 & 6.54 & 18.84 & 6.44 & 0.005 \\
\hline 4th finger active movement, $\mathrm{mm}$ & 21.28 & 6.07 & 20.28 & 4.95 & 0.144 \\
\hline 4th finger passive movement, $\mathrm{mm}$ & 22.50 & 6.40 & 22.16 & 5.74 & 0.430 \\
\hline 3rd finger active movement, $\mathrm{mm}$ & 21.34 & 5.76 & 20.84 & 5.04 & 0.390 \\
\hline 3rd finger passive movement, $\mathrm{mm}$ & 22.72 & 6.22 & 22.84 & 5.58 & 0.654 \\
\hline 2nd finger active movement, $\mathrm{mm}$ & 20.16 & 4.13 & 19.88 & 3.37 & 0.704 \\
\hline 2nd finger passive movement, $\mathrm{mm}$ & 21.69 & 4.69 & 22.22 & 4.43 & 0.218 \\
\hline 1st finger active movement, $\mathrm{mm}$ & 7.06 & 3.54 & 7.09 & 2.88 & 0.339 \\
\hline 1st finger passive movement, $\mathrm{mm}$ & 9.31 & 4.13 & 9.16 & 3.92 & 0.524 \\
\hline
\end{tabular}


Table 3. Cont.

\begin{tabular}{|c|c|c|c|c|c|}
\hline & \multicolumn{2}{|c|}{ No Stabilization } & \multicolumn{2}{|c|}{ Stabilization } & \multirow{2}{*}{$p^{*}$} \\
\hline & $\mathbf{M}$ & SD & $\mathbf{M}$ & SD & \\
\hline Wrist extension deficit, $\mathrm{mm}$ & 2.69 & 2.33 & 2.19 & 2.24 & 0.012 \\
\hline Wrist flexion deficit, mm & 2.16 & 2.25 & 1.63 & 1.83 & 0.064 \\
\hline 5th finger extension deficit, $\mathrm{mm}$ & 1.00 & 2.13 & 0.81 & 1.42 & 0.495 \\
\hline 5th finger flexion deficit, $\mathrm{mm}$ & 0.34 & 0.90 & 0.53 & 1.32 & 0.523 \\
\hline 4thfinger extension deficit, $\mathrm{mm}$ & 0.75 & 1.39 & 1.06 & 1.52 & 0.134 \\
\hline 4th finger flexion deficit, $\mathrm{mm}$ & 0.47 & 0.98 & 0.81 & 1.93 & 0.518 \\
\hline 3rd finger extension deficit, $\mathrm{mm}$ & 0.72 & 1.61 & 0.94 & 1.37 & 0.256 \\
\hline 3rd finger flexion deficit, mm & 0.66 & 1.15 & 1.06 & 2.03 & 0.296 \\
\hline 2nd finger extension deficit, $\mathrm{mm}$ & 0.97 & 1.58 & 1.50 & 2.49 & 0.145 \\
\hline 2nd finger flexion deficit, $\mathrm{mm}$ & 0.56 & 0.84 & 0.84 & 1.67 & 0.558 \\
\hline 1st finger extension deficit, $\mathrm{mm}$ & 0.72 & 1.46 & 0.59 & 1.01 & 0.726 \\
\hline 1st finger flexion deficit, $\mathrm{mm}$ & 1.53 & 2.42 & 1.47 & 3.25 & 0.099 \\
\hline Frequency of wrist movement (flexion to extension), cycles ${ }^{\#} / \mathrm{s}$ & 2.87 & 0.98 & 2.97 & 0.79 & 0.293 \\
\hline Wrist maximum ROM, mm & 23.64 & 7.27 & 26.38 & 8.35 & 0.003 \\
\hline Frequency of 5th finger movement (flexion to extension), cycles \#/s & 2.86 & 0.88 & 2.83 & 0.91 & 0.146 \\
\hline 5th finger maximum $\mathrm{ROM}, \mathrm{mm}$ & 20.41 & 7.88 & 19.44 & 7.81 & 0.362 \\
\hline Frequency of 4 th finger movement (flexion to extension), cycles $\# / s$ & 3.02 & 0.77 & 3.17 & 0.55 & 0.091 \\
\hline 4th finger maximum $\mathrm{ROM}, \mathrm{mm}$ & 23.32 & 9.58 & 22.11 & 10.71 & 0.364 \\
\hline Frequency of 3rd finger movement (from flexion to extension), cycles \#/s & 3.02 & 0.77 & 3.06 & 0.74 & 0.279 \\
\hline 3rd finger maximum $\mathrm{ROM}, \mathrm{mm}$ & 21.16 & 5.62 & 22.27 & 7.34 & 0.337 \\
\hline Frequency of 2nd finger movement (flexion to extension), cycles \#/s & 3.01 & 0.77 & 3.08 & 0.68 & 0.159 \\
\hline 2nd finger maximum ROM, $\mathrm{mm}$ & 19.00 & 4.23 & 19.52 & 5.20 & 0.896 \\
\hline Frequency of the 1st finger movement (flexion to extension), cycles $\# / \mathrm{s}$ & 2.49 & 1.14 & 2.43 & 1.14 & 0.741 \\
\hline 1st finger maximum ROM, mm & 13.78 & 6.05 & 15.60 & 6.85 & 0.084 \\
\hline Grip strength, kg & 35.25 & 11.88 & 34.33 & 11.99 & 0.286 \\
\hline
\end{tabular}

Legend: M-mean; ROM—range of motion; SD—standard deviation; ${ }^{*}$ Wilcoxon test; ${ }^{\#}$ one cycle = the movement from flexion to contraction. Notes: Passive and active ROM is a sum of all the finger flexion or extension angles (i.e., at the MCP, PIP and DIP joints); the extension deficit refers to the difference between passive and active ROM.

The effects of neurological deficits on the motor coordination of the hand and wrist were determined by comparing the stroke patients with a group of neurologically healthy subjects. Neurologically healthy subjects showed more significantly higher values (range of active wrist movement and frequency of wrist movements) in an unstable position. On the other hand, in a stabilized position, neurologically healthy subjects showed higher values only in the maximum range of wrist movement. Patients after stroke obtained much more results, important for the assessment of movement coordination, in a stable position. Even though the results show lower values than in healthy people, in the post-stroke group they are statistically significant and prove the advantage of a stable position of the trunk and upper limb for coordinated movement.

In stroke patients, the tone of the multifidus muscle was higher in the non-stabilized position than the stabilized position when the subject was moving their wrist or fingers (Table 4). Similarly, the tone of the multifidus, transverse abdominal and supraspinatus muscles was higher when moving the wrist or fingers in the non-stabilized position than the stabilized position in neurologically healthy subjects (Table 4). Neurologically healthy subjects had a higher level of muscle tone for all measured parameters than stroke patients in the non-stabilized position. However, in the stabilized position, neurologically healthy subjects exhibited a higher muscle tone for the multifidus and supraspinatus muscles during movement of the wrist or fingers than stroke patients. 
Table 4. Muscle tension parameters measured during wrist or finger movement, with and without stabilization of the trunk and upper limb.

\begin{tabular}{|c|c|c|c|c|c|c|c|c|c|c|}
\hline & \multicolumn{5}{|c|}{$\begin{array}{l}\text { Stroke Group } \\
\quad(n=34)\end{array}$} & \multicolumn{5}{|c|}{$\begin{array}{l}\text { Neurologically Healthy Group } \\
(n=32)\end{array}$} \\
\hline & \multicolumn{2}{|c|}{ No Stabilization } & \multicolumn{2}{|c|}{ Stabilization } & \multirow{2}{*}{$p^{*}$} & \multicolumn{2}{|c|}{ No Stabilization } & \multicolumn{2}{|c|}{ Stabilization } & \multirow{2}{*}{$p^{*}$} \\
\hline & $\mathbf{M}$ & SD & $\mathbf{M}$ & SD & & $\mathbf{M}$ & SD & $\mathbf{M}$ & SD & \\
\hline \multicolumn{11}{|l|}{$\begin{array}{l}\text { Tension measured during wrist } \\
\text { movement }\end{array}$} \\
\hline Multifidus muscle tension, $\mu \mathrm{V}$ & 76.84 & 100.28 & 42.36 & 34.15 & 0.028 & 130.73 & 77.72 & 75.80 & 79.77 & $<0.001$ \\
\hline Transverse muscle tension, $\mu \mathrm{V}$ & 69.52 & 80.54 & 58.60 & 73.99 & 0.099 & 141.40 & 165.86 & 65.54 & 70.46 & $<0.001$ \\
\hline $\begin{array}{l}\text { Supraspinatus muscle tension, } \mu \mathrm{V} \\
\text { Tension measured during finger } \\
\text { movement }\end{array}$ & 81.15 & 73.16 & 83.88 & 61.64 & 0.278 & 170.19 & 95.92 & 120.78 & 47.91 & $<0.001$ \\
\hline Multifidus muscle tension, $\mu \mathrm{V}$ & 78.30 & 100.43 & 42.74 & 32.69 & 0.014 & 126.77 & 80.21 & 70.43 & 63.37 & $<0.001$ \\
\hline Transverse muscle tension, $\mu \mathrm{V}$ & 63.15 & 68.06 & 51.57 & 57.63 & 0.126 & 137.38 & 166.16 & 62.54 & 66.74 & $<0.001$ \\
\hline Supraspinatus muscle tension, $\mu \mathrm{V}$ & 82.29 & 72.52 & 80.34 & 61.04 & 0.215 & 165.55 & 95.03 & 115.84 & 52.19 & $<0.001$ \\
\hline
\end{tabular}

Legend: $\mathrm{M}$-mean; SD—standard deviation; * Wilcoxon test.

In stroke group in whom the affected/dominant hand was examined, the range of flexion of fingers 3 and 4 was higher in the stabilized position (Table 5). Meanwhile, the range of the active movement of finger 4 was higher in the non-stabilized position. In subjects in whom an affected/non-dominant hand was examined, higher values were found for the frequency of movements from flexion to extension of fingers 2, 3, 4, 5, were observed in a stabilized position compared to a non-stabilized position. If the affected/dominant hand was tested, stroke group showed no significant differences in muscle tone depending on the position (i.e., seated or supine; Table 6). However, if the affected/non-dominant extremity was tested, higher muscle tones were found in a non-stabilized position than the stabilized position for the transverse muscle when moving the wrist and for the multifidus and transverse muscles when moving the fingers. The test result may be influenced by a small group of patients with a dominant (18) and non-dominant (16) hand.

Table 5. Effect of hand dominance on motor coordination of the hand and wrist in stroke patients with and without stabilization of the trunk and upper limb.

\begin{tabular}{|c|c|c|c|c|c|c|c|c|c|c|}
\hline & \multicolumn{5}{|c|}{ Affected/Dominant Hand } & \multicolumn{5}{|c|}{ Affected/Non-Dominant } \\
\hline & \multicolumn{2}{|c|}{ No Stabilization } & \multicolumn{2}{|c|}{ Stabilization } & \multirow{2}{*}{$p^{*}$} & \multicolumn{2}{|c|}{ No Stabilization } & \multicolumn{2}{|c|}{ Stabilization } & \multirow{2}{*}{$p^{*}$} \\
\hline & $\mathbf{M}$ & SD & $\mathbf{M}$ & SD & & $\mathbf{M}$ & SD & $\mathbf{M}$ & SD & \\
\hline Range of active movement of the wrist, $\mathrm{mm}$ & 16.94 & 5.74 & 17.17 & 6.14 & 0.755 & 19.00 & 6.62 & 20.50 & 6.14 & 0.342 \\
\hline Range of passive movement of the wrist, $\mathrm{mm}$ & 24.78 & 3.74 & 24.17 & 4.82 & 0.660 & 26.00 & 3.80 & 26.75 & 3.75 & 0.549 \\
\hline 5 th finger active movement, $\mathrm{mm}$ & 16.17 & 7.23 & 15.56 & 8.10 & 0.552 & 23.19 & 9.67 & 19.81 & 7.77 & 0.083 \\
\hline 5 th finger passive movement, $\mathrm{mm}$ & 19.17 & 6.71 & 19.56 & 7.60 & 0.856 & 28.19 & 8.98 & 23.19 & 7.64 & 0.017 \\
\hline 4 th finger active movement, $\mathrm{mm}$ & 21.89 & 7.32 & 19.67 & 7.90 & 0.021 & 24.31 & 7.46 & 23.69 & 7.36 & 0.931 \\
\hline 4 th finger passive movement, $\mathrm{mm}$ & 24.61 & 6.42 & 23.61 & 6.71 & 0.261 & 31.00 & 5.45 & 27.31 & 6.52 & 0.154 \\
\hline 3rd finger active movement, $\mathrm{mm}$ & 22.61 & 5.65 & 21.56 & 5.64 & 0.120 & 23.31 & 6.63 & 23.50 & 6.09 & 0.856 \\
\hline 3rd finger passive movement, $\mathrm{mm}$ & 24.67 & 5.36 & 25.44 & 5.19 & 0.324 & 29.88 & 4.63 & 26.94 & 5.97 & 0.111 \\
\hline 2nd finger active movement, $\mathrm{mm}$ & 19.28 & 5.03 & 18.50 & 5.69 & 0.377 & 22.19 & 6.53 & 22.31 & 5.28 & 0.888 \\
\hline 2nd finger passive movement, $\mathrm{mm}$ & 25.17 & 6.39 & 23.33 & 4.17 & 0.436 & 29.06 & 3.42 & 27.06 & 3.97 & 0.086 \\
\hline 1st finger active movement, $\mathrm{mm}$ & 8.89 & 5.08 & 8.06 & 4.11 & 0.494 & 9.50 & 6.31 & 8.88 & 5.70 & 0.875 \\
\hline 1st finger passive movement, $\mathrm{mm}$ & 12.11 & 5.87 & 12.56 & 5.45 & 0.867 & 13.31 & 5.86 & 13.44 & 6.19 & 0.979 \\
\hline Wrist extension deficit, $\mathrm{mm}$ & 4.56 & 3.37 & 4.28 & 3.36 & 0.393 & 3.81 & 4.15 & 3.19 & 3.78 & 0.503 \\
\hline Wrist flexion deficit, $\mathrm{mm}$ & 3.28 & 2.08 & 2.72 & 3.43 & 0.107 & 3.19 & 3.29 & 3.06 & 2.72 & 0.840 \\
\hline 5 th finger extension deficit, $\mathrm{mm}$ & 2.56 & 2.28 & 3.17 & 2.94 & 0.728 & 3.56 & 3.05 & 2.56 & 2.85 & 0.275 \\
\hline 5 th finger flexion deficit, $\mathrm{mm}$ & 0.44 & 1.20 & 0.83 & 1.62 & 0.394 & 1.44 & 2.56 & 0.81 & 1.56 & 0.438 \\
\hline 4thfinger extension deficit, $\mathrm{mm}$ & 2.33 & 2.54 & 2.11 & 2.08 & 0.887 & 3.38 & 3.07 & 2.00 & 1.59 & 0.091 \\
\hline 4th finger flexion deficit, $\mathrm{mm}$ & 0.39 & 0.70 & 1.83 & 2.66 & 0.028 & 3.31 & 5.30 & 1.63 & 2.22 & 0.349 \\
\hline 3rd finger extension deficit, $\mathrm{mm}$ & 1.78 & 2.05 & 1.78 & 2.24 & 0.681 & 3.50 & 4.24 & 1.88 & 1.63 & 0.180 \\
\hline 3rd finger flexion deficit, $\mathrm{mm}$ & 0.28 & 0.58 & 2.11 & 2.91 & 0.003 & 3.06 & 4.14 & 1.56 & 1.86 & 0.254 \\
\hline 2nd finger extension deficit, $\mathrm{mm}$ & 4.00 & 5.22 & 1.78 & 2.05 & 0.112 & 3.25 & 3.53 & 2.13 & 1.78 & 0.284 \\
\hline 2nd finger flexion deficit, $\mathrm{mm}$ & 1.89 & 1.97 & 3.06 & 2.94 & 0.234 & 3.63 & 4.52 & 2.63 & 2.92 & 0.309 \\
\hline 1st finger extension deficit, $\mathrm{mm}$ & 0.94 & 0.94 & 1.06 & 1.00 & 0.719 & 1.63 & 2.25 & 1.38 & 1.36 & 0.632 \\
\hline 1st finger flexion deficit, $\mathrm{mm}$ & 2.28 & 3.83 & 3.44 & 3.68 & 0.452 & 2.19 & 3.15 & 3.19 & 4.45 & 0.476 \\
\hline
\end{tabular}


Table 5. Cont.

\begin{tabular}{|c|c|c|c|c|c|c|c|c|c|c|}
\hline & \multicolumn{5}{|c|}{ Affected/Dominant Hand } & \multicolumn{5}{|c|}{ Affected/Non-Dominant } \\
\hline & \multicolumn{2}{|c|}{ No Stabilization } & \multicolumn{2}{|c|}{ Stabilization } & \multirow{2}{*}{$p^{*}$} & \multicolumn{2}{|c|}{ No Stabilization } & \multicolumn{2}{|c|}{ Stabilization } & \multirow{2}{*}{$p^{*}$} \\
\hline & $\mathbf{M}$ & SD & $\mathbf{M}$ & SD & & $\mathbf{M}$ & SD & $\mathbf{M}$ & SD & \\
\hline $\begin{array}{l}\text { Frequency of wrist movement (flexion to } \\
\text { extension), cycles } \# / s\end{array}$ & 1.04 & 0.69 & 1.08 & 0.74 & 0.959 & 1.28 & 0.74 & 1.35 & 0.98 & 0.581 \\
\hline Wrist maximum ROM, mm & 20.44 & 13.82 & 20.69 & 11.73 & 0.039 & 18.92 & 5.97 & 19.10 & 5.96 & 0.897 \\
\hline $\begin{array}{l}\text { Frequency of } 5 \text { th finger movement (flexion to } \\
\text { extension), cycles } \# / s\end{array}$ & 1.44 & 0.95 & 1.53 & 0.87 & 0.162 & 1.67 & 1.00 & 1.83 & 1.02 & 0.036 \\
\hline 5th finger maximum ROM, mm & 16.67 & 8.20 & 15.09 & 9.04 & 0.184 & 19.59 & 8.82 & 19.97 & 12.24 & 0.438 \\
\hline $\begin{array}{l}\text { Frequency of } 4 \text { th finger movement (flexion to } \\
\text { extension), cycles } \# / s\end{array}$ & 1.46 & 0.94 & 1.56 & 0.90 & 0.162 & 1.66 & 0.99 & 1.83 & 1.03 & 0.029 \\
\hline 4th finger maximum $\mathrm{ROM}, \mathrm{mm}$ & 21.31 & 6.52 & 19.46 & 8.60 & 0.088 & 24.26 & 9.45 & 21.80 & 6.69 & 0.121 \\
\hline $\begin{array}{l}\text { Frequency of 3rd finger movement (from } \\
\text { flexion to extension), cycles } \# / s\end{array}$ & 1.46 & 0.94 & 1.55 & 0.89 & 0.162 & 1.62 & 1.04 & 1.83 & 1.03 & 0.018 \\
\hline 3rd finger maximum ROM, mm & 21.83 & 5.30 & 19.87 & 6.25 & 0.149 & 22.18 & 6.53 & 21.03 & 5.89 & 0.173 \\
\hline $\begin{array}{l}\text { Frequency of } 2 \text { nd finger movement (flexion } \\
\text { to extension), cycles } \# / s\end{array}$ & 1.46 & 0.94 & 1.56 & 0.90 & 0.162 & 1.63 & 1.05 & 1.83 & 1.03 & 0.018 \\
\hline 2nd finger maximum ROM, mm & 18.04 & 5.74 & 17.36 & 6.58 & 0.632 & 19.31 & 6.41 & 18.74 & 5.24 & 0.552 \\
\hline $\begin{array}{l}\text { Frequency of the } 1 \text { st finger movement } \\
\text { (flexion to extension), cycles } \# / s\end{array}$ & 1.17 & 0.89 & 1.21 & 1.08 & 0.585 & 1.18 & 1.04 & 1.18 & 1.03 & 0.622 \\
\hline 1st finger maximum ROM, mm & 8.51 & 4.80 & 8.12 & 3.92 & 0.744 & 10.19 & 4.76 & 8.98 & 4.66 & 0.255 \\
\hline Grip strength, kg & 15.54 & 12.28 & 16.27 & 12.74 & 0.372 & 21.44 & 16.03 & 22.34 & 15.50 & 0.088 \\
\hline
\end{tabular}

Legend: M-mean; ROM-range of motion; SD—standard deviation; ${ }^{*}$ Wilcoxon test; ${ }^{*}$ one cycle $=$ the movement from flexion to contraction. Notes: Passive and active ROM is a sum of all the finger flexion or extension angles (i.e., at the MCP, PIP and DIP joints); the extension deficit refers to the difference between passive and active ROM.

Table 6. Effect of hand dominance on muscle tension in stroke patients with and without stabilization of the trunk and upper limb.

\begin{tabular}{|c|c|c|c|c|c|c|c|c|c|c|}
\hline \multirow{3}{*}{ Muscle Tension } & \multicolumn{5}{|c|}{ Affected/Dominant Hand } & \multicolumn{5}{|c|}{ Affected/Non-Dominant Hand } \\
\hline & \multicolumn{2}{|c|}{ No Stabilization } & \multicolumn{2}{|c|}{ Stabilization } & \multirow{2}{*}{$p^{*}$} & \multicolumn{2}{|c|}{ No Stabilization } & \multicolumn{2}{|c|}{ Stabilization } & \multirow{2}{*}{$p^{*}$} \\
\hline & $\mathbf{M}$ & SD & $\mathbf{M}$ & SD & & $\mathbf{M}$ & SD & $\mathbf{M}$ & SD & \\
\hline \multicolumn{11}{|l|}{$\begin{array}{l}\text { Tension measured during wrist } \\
\text { movement }\end{array}$} \\
\hline Multifidus muscle tension, $\mu \mathrm{V}$ & 63.47 & 80.52 & 42.85 & 35.12 & 0.199 & 91.88 & 119.66 & 41.82 & 34.17 & 0.063 \\
\hline Transverse muscle tension, $\mu \mathrm{V}$ & 57.37 & 54.30 & 70.43 & 94.18 & 0.679 & 83.19 & 102.73 & 45.29 & 40.43 & 0.044 \\
\hline $\begin{array}{l}\text { Supraspinatus muscle tension, } \mu \mathrm{V} \\
\text { Tension measured during finger } \\
\text { movement }\end{array}$ & 69.81 & 60.64 & 81.34 & 63.93 & 0.647 & 93.92 & 85.32 & 86.74 & 60.92 & 0.352 \\
\hline Multifidus muscle tension, $\mu \mathrm{V}$ & 62.16 & 80.32 & 43.69 & 33.89 & 0.199 & 96.45 & 119.23 & 41.66 & 32.37 & 0.030 \\
\hline Transverse muscle tension, $\mu \mathrm{V}$ & 51.47 & 52.89 & 59.84 & 71.18 & 0.983 & 76.30 & 81.69 & 42.27 & 37.28 & 0.026 \\
\hline Supraspinatus muscle tension, $\mu \mathrm{V}$ & 71.75 & 61.09 & 75.16 & 64.24 & 0.396 & 94.14 & 84.01 & 86.17 & 58.74 & 0.326 \\
\hline
\end{tabular}

Legend: M-mean; SD—standard deviation; * Wilcoxon test.

\section{Discussion}

This study shows that coordination of the hand and wrist in stroke patients were better with passive stabilization of the trunk and upper limb. Stabilization of the trunk and upper limb turned out to be also important for improving the coordination of the affected/non-dominant hands in stroke patients. Motor coordination was assessed using the HandTutor ${ }^{\mathrm{TM}}$ as well as at work Carmeli at al. although in their work the device, apart from the function of the test, was assessed in terms of the effects of therapy [43]. Commonly accepted scales and tests, Trunk Control Test, the Fugl-Meyer scale and the MAS assessment were used to analyze the functional conditions of the respondents [40-42,44].

In general, in the conditions of stabilization of the trunk and upper limb, a significant improvement in coordination, especially of the fingers, was noted with the HandTutor parameters in the group of people after stroke. Healthy people in a stable position achieved only a significantly greater range of maximum wrist motion. Patients after stroke obtained much more results, important for the assessment of movement coordination, in a stable position and although the results show lower values than in healthy people, the post-stroke are statistically significant and prove the advantage of a stable position for achieving coordinated movement of the distal part of the upper limb.

Passive stabilization of the trunk (or trunk restraint) could allow stroke patients to access "normal" movement patterns that may have been lost due to neurological impair- 
ment [27]. In the cited work the authors evaluate the shoulder and elbow joint during trunk restraint and report improvement in ranges of elbow and shoulder joint movement increased in both groups [27].

Overall, in all subjects, the tension of the deep muscles of the trunk and the supraspinatus muscle of the shoulder was higher in the seated, non-stabilized position than in the supine, stabilized positions. In addition, neurologically healthy subjects had a higher level of muscle tone than stroke patients while stroke, in most cases, presented higher results of passive movement which is probably before that the stroke patients have lower tension of muscles than healthy people [45]. Stroke patients have had also higher deficits of finger extension what is a consequence of the difference between the active and passive extension. Stroke patients usually cannot perform fully active fingers extension, because of weaker extensors than flexors [28]. Due to disturbed muscle activations, particularly of the extrinsic extensors, were significantly affected by postural changes of the interphalangeal, but not metacarpophalangeal, joints [26].

Recent studies show that in order to improve the functioning of the hand, one should strive to maintain and restore equal results in terms of grasping and squeezing strength of the dominant and non-dominant hand $[46,47]$. Moreover, researchers suggest that upper limb rehabilitation exercises after a stroke include the non-dominant and dominant arms of the dominant upper limb [48]. In this study, the effect of stabilization on the parameters of motor coordination in dominant and non-dominant limbs in stroke patients was assessed. However, only the affected upper limb was examined, the opposite limb was not tested, which is a limitation of research in this topic.

Correspondingly, this study showed the supraspinatus muscle demonstrated higher activity than the core stability muscles when the hand or wrist are moving. Greater activation of the supraspinatus muscle was observed in a stabilized position, and this corresponds to improved coordination and strength of the upper extremity.

Indeed, core or trunk stability has been shown to affect the motor coordination of the flexion of the hip and shoulder of the non-paretic side and trunk flexion and extension chronic stage stroke patients and healthy controls [49]. Garrison, B. and Wade, E. in 2015 presented studies on the ability of inertial sensors to record measures of limb coordination in non-disabled persons while performing ADL-inspired tasks. In this way, they assessed the limb coordination as measured by the features of the time and frequency domains with regard to the tasks of the upper limbs and assessed the relative sensitivity of these measures to different task types [6].

In this study, in the sitting and lying position, the position of the upper limb was the same (in adduction of the humeral joint, with the elbow bent in the intermediate position between pronation and supination of the forearm, the wrist and the hand were free-no stabilization). Furthermore, both in patients after a stroke and in healthy ones in the sitting position (without stabilization) the tension muscles the transverse abdominal and multifidus were higher than in the supine (stable) position. Only the supraspinatus in patients after a stroke showed, insignificant, though higher tension when the wrist was working in a stable position (lying down). It seems that the position of the body is important for improving the parameters of movement coordination, expressed primarily in the frequency of movement.

In this study, statistically higher results concerning motor coordination and grip force were obtained for the non-dominant hand under the conditions of stabilization of the trunk and upper limb. At the same time, comparing the muscle tension analyzed for the dominant and non-dominant limbs of stroke patients, both during wrist and finger movements, statistically higher tensions of the transversus abdominis and multifidus muscles were obtained in conditions without stabilization. In addition, the supraspinatus tension was higher in these conditions, but this result turned out to be statistically insignificant.

In addition, this study showed that passive stabilization of the upper limb (i.e., holding it close to the body) is also important for restoring the movement and function of the hand after a stroke. Indeed, reduced muscle tension often leads to a characteristic body position 
in stroke patients, typically involving a protractive position of the shoulders. Moreover, recent studies show a causal relationship between stroke and subacromial impingement syndrome, which leads to irritation of the supraspinatus muscle [30,31]. Therefore, in stroke patients, the muscle that plays an important role in stabilizing the upper extremity is usually in a highly unfavorable condition for its functional restoration. The results of this work clearly emphasize that the stable position of the trunk and the examined nondominant limb improves the parameters of motor coordination with lower trunk muscle tension in this position. In post-stroke patients the supraspinatus tension was higher in the stable position, although not statistically significant, but this is what seems important in stroke patients. The generally lower muscle tension in people after a stroke, in the supine position for supraspinatus, behaves differently and is higher. It is as if in this position they were trying to compensate for the deficiencies by using stronger muscle groups (flexion synergy), abductors, that is, e.g., supraspinatus, for the distal movement of the upper limb. Kordelaar et al. in 2012 was to identify how pathological limb synergies between shoulder and elbow movements interact with compensatory trunk movements during a functional movement with the paretic upper limb after stroke [50]. The importance of limb movement in restoring fitness after a stroke has already been emphasized. Kwakkel et al. (2003), based on the Fugl-Meyer score for the flaccid arm, investigated that optimal prediction of arm performance at 6 months can be made within 4 weeks after the onset of stroke [2]. Nijland et al. (2021) reported that shoulders abduction was associated with the recovery of distal movements of the upper limb since the movement of the proximal joint favored the recovery of the distal ones. In addition, the authors observed that the preservation of shoulder abduction and finger extension movements reflected the level of integrity of the corticospinal tract $[5,31,32]$. Smania et al. in 2009 proved that the active finger extension scale is a strong early predictor of recovery of daily life autonomy in patients with stroke [51].

The presence of shoulder abduction as a determinant for upper limb function may reflect the intralimb neural coupling between proximal and distal segments in motor control [32]. The challenge for improving stroke recovery is understanding how to optimally engage and modify surviving neural networks to provide new response strategies that compensate for tissue loss following injury [52]. The basis of this improvement is the plasticity of the brain [53].

Overall, this study indicates that placing patients in the supine position with the upper limb (shoulder) stabilized beside their body during rehabilitation work may help them to access latent movement patterns that could have been lost due to stroke. However, further investigation is required to quantitatively assess the benefits of such passive stabilization with in a stroke rehabilitation program involving a large cohort of patients.

\subsection{The Value of the Study}

Our study found that passive stabilization of the shoulder in addition to the trunk during stroke rehabilitation is important to restore the correct movement pattern and regain function of the hand.

\subsection{Limitations of the Study}

The limitation of the study was the examination of only one of the muscles in the shoulder girdle, the supraspinatus. Certainly, examining more muscles in the shoulder girdle and upper limb would allow for more conclusions.

The examination may also be limited by examining patients in a specific functional state (e.g., muscles tension MAS 1/1+), however, in order to assess the coordination of movement and the grip strength, a functional state is needed that is characterized by the possibility of any movement in the examined wrist joint and fingers. However, it would be good to investigate functionally diverse groups of patients. The research could provide more evidence. 
Only the affected upper limb was examined. It was determined whether or not it was the dominant limb, but the opposite upper limb was not examined. Examination of the opposite limb in conditions with and without stabilization would increase the value of the study and is planned in future research.

\subsection{Clinical Messages}

- Passive stabilization of both the shoulder and the trunk can improve hand and wrist coordination in patients following a stroke.

- Placing patients in the supine position with the upper arm held beside their body during rehabilitation work may help them to access latent movement patterns lost due to stroke.

\section{Conclusions}

Passive stabilization of the trunk and upper extremity should be used in rehabilitation programs to restore coordination of movement in the distal part of upper limb.

Author Contributions: Conceptualization, A.O. Data curation, A.O.; formal analysis, A.O.; funding acquisition, A.O.; investigation, A.O.; methodology, A.O.; project administration, A.O.; supervision, A.O. and A.T.-B.; literature search A.O. and A.T.-B.; final corrections: A.O. and A.T.-B. All authors have read and agreed to the published version of the manuscript.

Funding: There was no financial support for this work.

Institutional Review Board Statement: All procedures performed in studies involving human participants were in accordance with the ethical standards of the institutional research committee and with the 1964 Helsinki Declaration and its later amendments or comparable ethical standards. Ethical review committee statement of Commission of Ethics of the Military Medical Institute (approval number 6/MMI/2020).

Informed Consent Statement: Informed consent was obtained from all individual adult participants included in the study.

Data Availability Statement: Data available on request from corresponding author.

Acknowledgments: I would like to thank the company EGZOTech a manufacturer of medical equipment in Gliwice, Poland for lending the Luna EMG device.

Conflicts of Interest: The authors declare that they have no conflict of interest.

\section{References}

1. Lai, C.H.; Sung, W.H.; Chiang, S.L.; Lu, L.H.; Lin, C.H.; Tung, Y.C.; Lin, C.H. Bimanual coordination deficits in hands following stroke and their relationship with motor and functional performance. J. Neuroeng. Rehabil. 2019, 16, 101. [CrossRef]

2. Kwakkel, G.; Kollen, B.J.; van der Grond, J.; Prevo, A.J. Probability of regaining dexterity in the flaccid upper limb: Impact of severity of paresis and time since onset in acute stroke. Stroke 2003, 34, 2181-2186. [CrossRef]

3. Santisteban, L.; Térémetz, M.; Bleton, J.P.; Baron, J.C.; Maier, M.A.; Lindberg, P.G. Upper Limb Outcome Measures Used in Stroke Rehabilitation Studies: A Systematic Literature Review. PLoS ONE 2016, 11, e0154792. [CrossRef] [PubMed]

4. Hayward, K.S.; Brauer, S.G. Dose of arm activity training during acute and subacute rehabilitation post stroke: A systematic review of the literature. Clin. Rehabil. 2015, 29, 1234-1243. [CrossRef] [PubMed]

5. Kwakkel, G.; Kollen, B. Predicting improvement in the upper paretic limb after stroke: A longitudinal prospective study. Restor. Neurol. Neurosci. 2007, 25, 453-460. [PubMed]

6. Garrison, B.; Wade, E. Relative accuracy of time and frequency domain features to quantify upper extremity coordination. In Proceedings of the 2015 37th Annual International Conference of the IEEE Engineering in Medicine and Biology Society (EMBC), Milan, Italy, 25-29 August 2015; pp. 4958-4961.

7. Scano, A.; Dardari, L.; Molteni, F.; Giberti, H.; Tosatti, L.M.; d'Avella, A. A Comprehensive Spatial Mapping of Muscle Synergies in Highly Variable Upper-Limb Movements of Healthy Subjects. Front. Physiol. 2019, 10, 1231. [CrossRef] [PubMed]

8. Langhorne, P.; Coupar, F.; Pollock, A. Motor recovery after stroke: A systematic review. Lancet Neurol. 2009, 8, 741-754. [CrossRef]

9. Kwakkel, G.; Meskers, C.G.; van Wegen, E.E.; Lankhorst, G.J.; Geurts, A.C.; van Kuijk, A.A.; Lindeman, E.; Visser-Meily, A.; de Vlugt, E.; Arendzen, J.H. Impact of early applied upper limb stimulation: The EXPLICIT-stroke programme design. BMC Neurol. 2008, 8, 49. [CrossRef] [PubMed] 
10. Fluet, G.; Qiu, Q.; Patel, J.; Mont, A.; Cronce, A.; Yarossi, M.; Merians, A.; Adamovich, S. Virtual Rehabilitation of the Paretic Hand and Arm in Persons With Stroke: Translation From Laboratory to Rehabilitation Centers and the Patient's Home. Front. Neurol. 2021, 12, 1-10. [CrossRef]

11. Wolf, S.L.; Winstein, C.J.; Miller, J.P.; Taub, E.; Uswatte, G.; Morris, D.; Giuliani, C.; Light, K.E.; Nichols-Larsen, D. Effect of constraint-induced movement therapy on upper extremity function 3 to 9 months after stroke: The EXCITE randomized clinical trial. JAMA 2006, 296, 2095-2104. [CrossRef]

12. Behm, D.G.; Drinkwater, E.J.; Willardson, J.M.; Cowley, P.M. The use of instability to train the core musculature. Appl. Physiol. Nutr. Metab. 2010, 35, 91-108. [CrossRef]

13. Hibbs, A.E.; Thompson, K.G.; French, D.; Wrigley, A.; Spears, I. Optimizing performance by improving core stability and core strength. Sports Med. 2008, 38, 995-1008. [CrossRef]

14. Cotoros, D. Biomechanical Analyzes of Human Body Stability and Equilibrium. In Proceedings of the World Congress on Engineering 2010, WCE 2010, London, UK, 30 June-2 July 2010; Volume II.

15. Knudson, D. Fundamentals of Biomechanics; Kluwer Academics/Plenum Publishers: New York, NY, USA, 2003; pp. 178-188. ISBN $0-306-47474-3$

16. Lennon, S.; Baxter, D.; Ashburn, A. Physiotherapy based on the Bobath concept in stroke rehabilitation: A survey within the UK. Disabil. Rehabil. 2001, 23, 254-262. [CrossRef]

17. Graham, J.V.; Eustace, C.; Brock, K.; Swain, E.; Irwin-Carruthers, S. The Bobath concept in contemporary clinical practice. Top. Stroke Rehabil. 2009, 16, 57-68. [CrossRef] [PubMed]

18. Lennon, S.; Ashburn, A. The Bobath concept in stroke rehabilitation: A focus group study of the experienced physiotherapists' perspective. Disabil. Rehabil. 2000, 22, 665-674. [CrossRef] [PubMed]

19. Farjoun, N.; Mayston, M.; Florencio, L.L.; Fernández-De-Las-Peñas, C.; Palacios-Ceña, D. Essence of the Bobath concept in the treatment of children with cerebral palsy. A qualitative study of the experience of Spanish therapists. Physiother. Theory Pract. 2020, 1-13. [CrossRef] [PubMed]

20. Luke, C.; Dodd, K.J.; Brock, K. Outcomes of the Bobath concept on upper limb recovery following stroke. Clin. Rehabil. 2004, 18, 888-898. [CrossRef]

21. Wattananona, P. Core Stabilization Exercise and Movement System Impairment Approaches for Patients with Movement Control Impairment: A Review Article. Asia-Pac. J. Sci. Technol. 2015, 20, 480-492.

22. Van Criekinge, T.; Saeys, W.; Hallemans, A.; Velghe, S.; Viskens, P.J.; Vereeck, L.; De Hertogh, W.; Truijen, S. Trunk biomechanics during hemiplegic gait after stroke: A systematic review. Gait Posture 2017, 54, 133-143. [CrossRef]

23. Hodges, P.W.; Richardson, C.A. Contraction of the abdominal muscles associated with movement of the lower limb. Phys. Ther. 1997, 77, 132-142; discussion 134-142. [CrossRef]

24. Jirsa, V.K.; Fink, P.; Foo, P.; Kelso, J.A. Parametric stabilization of biological coordination: A theoretical model. J. Biol. Phys. 2000, 26, 85-112. [CrossRef]

25. Okunribido, O.O.; Haslegrave, C.M. Ready steady push—A study of the role of arm posture in manual exertions. Ergonomics 2008, 51, 192-216. [CrossRef]

26. Lee, S.W.; Qiu, D.; Fischer, H.C.; Conrad, M.O.; Kamper, D.G. Modulation of finger muscle activation patterns across postures is coordinated across all muscle groups. J. Neurophysiol. 2020, 124, 330-341. [CrossRef]

27. Michaelsen, S.M.; Luta, A.M.; Roby-Brami, A.; Levin, M.F. Effect of trunk restraint on the recovery of reaching movements in hemiparetic patients. Stroke 2001, 32, 1875-1883. [CrossRef]

28. Hardwick, D.D.; Lang, C.E. Scapular and humeral movement patterns of people with stroke during range-of-motion exercises. J. Neurol. Phys. Ther. 2011, 35, 18-25. [CrossRef] [PubMed]

29. Thigpen, C.A.; Shaffer, M.A.; Gaunt, B.W.; Leggin, B.G.; Williams, G.R.; Wilcox, R.B., III. The American Society of Shoulder and Elbow Therapists' consensus statement on rehabilitation following arthroscopic rotator cuff repair. J. Shoulder Elb. Surg. 2016, 25, 521-535. [CrossRef] [PubMed]

30. Brunnstrom, S. Movement Therapy in Hemiplegia: A Neurophysiological Approach; Harper and Row: New York, NY, USA, 1970.

31. Ellis, M.D.; Sukal-Moulton, T.; Dewald, J.P. Progressive shoulder abduction loading is a crucial element of arm rehabilitation in chronic stroke. Neurorehabilit. Neural Repair 2009, 23, 862-869. [CrossRef] [PubMed]

32. Nijland, R.H.; van Wegen, E.E.; Harmeling-van der Wel, B.C.; Kwakkel, G. On behalf of the EPOS Investigators. Presence of Finger Extension and Shoulder Abduction Within 72 Hours After Stroke Predicts Functional Recovery Early Prediction of Functional Outcome After Stroke: The EPOS Cohort Study. Stroke 2010, 41, 745-750. [CrossRef] [PubMed]

33. Tanzarella, S.; Muceli, S.; Del Vecchio, A.; Casolo, A.; Farina, D. Non-invasive analysis of motor neurons controlling the intrinsic and extrinsic muscles of the hand. J. Neural Eng. 2020, 17, 046033. [CrossRef] [PubMed]

34. Weiler, J.; Gribble, P.L.; Pruszynski, J.A. Rapid feedback responses are flexibly coordinated across arm muscles to support goal-directed reaching. J. Neurophysiol. 2018, 119, 537-547. [CrossRef] [PubMed]

35. Rand, M.K.; Rentsch, S. Eye-Hand Coordination during Visuomotor Adaptation with Different Rotation Angles: Effects of Terminal Visual Feedback. PLoS ONE 2016, 11, e0164602. [CrossRef]

36. Delph, M.A.; Fischer, S.A.; Gauthier, P.W.; Luna, C.H.M.; Clancy, E.A.; Fischer, G.S. A soft robotic exomusculature glove with integrated sEMG sensing for hand rehabilitation. In Proceedings of the 2013 IEEE 13th International Conference on Rehabilitation Robotics (ICORR), Seattle, WA, USA, 24-26 June 2013. 
37. Golaszewski, S.; Kremser, C.H.; Wagner, M.; Felber, S.; Aichner, F.; Dimitrijevic, M.M. Functional magnetic resonance imaging of the human motor cortex before and after whole-hand afferent electrical stimulation. Scand. J. Rehabil. Med. 1999, 31, 165-173. [CrossRef]

38. Oluigbo, C.O.; Salma, A.; Rezai, A.R. Deep brain stimulation for neurological disorders. IEEE Rev. Biomed. Eng. 2012, 5, 88-99. [CrossRef] [PubMed]

39. Katayama, Y. Deep brain stimulation therapy for involuntary movements. Rinsho Shinkeigaku Clin. Neurol. 2001, 41, 1079-1080.

40. Collin, C.; Wade, D. Assessing motor impairment after stroke: A pilot reliability study. J. Neurol. Neurosurg. Psychiatry 1990, 53, 576-579. [CrossRef] [PubMed]

41. Sanford, J.; Moreland, J.; Swanson, L.R.; Stratford, P.W.; Gowland, C. Reliability of the Fugl-Meyer assessment for testing motor performance in patients following stroke. Phys. Ther. 1993, 73, 447-454. [CrossRef]

42. Bohannon, R.; Smith, M. Interrater reliability of a modified Ashworth scale of muscle spasticity. Phys. Ther. 1987, 67, 206. [CrossRef]

43. Carmeli, E.; Peleg, S.; Bartur, G.; Elbo, E.; Vatine, J.J. HandTutor ${ }^{\mathrm{TM}}$ enhanced hand rehabilitation after stroke-a pilot study. Physiother. Res. Int. 2011, 16, 191-200. [CrossRef]

44. Franchignoni, F.P.; Tesio, L.; Ricupero, C.; Martino, M.T. Trunk control test as an early predictor of stroke rehabilitation outcome. Stroke 1997, 28, 1382-1385. [CrossRef]

45. Andersen, L.; Zeeman, P.; Jørgensen, J.R.; Bech-Pedersen, D.T.; Sørensen, J.; Kjær, M.; Andersen, J. Effects of intensive physical rehabilitation on neuromuscular adaptations in adults with poststroke hemiparesis. J. Strength Cond. Res. 2011, 25, $2808-2817$. [CrossRef] [PubMed]

46. Armstrong, C.A.; Oldham, J.A. A Comparison of Dominant and Non-Dominant Hand Strengths. J. Hand Surg. 1999, $24,421-425$. [CrossRef] [PubMed]

47. El-Gohary, T.M.; Abd Elkader, S.M.; Al-Shenqiti, A.M.; Ibrahim, M.I. Assessment of hand-grip and key-pinch strength at three arm positions among healthy college students: Dominant versus non-dominant hand. J. Taibah Univ. Med. Sci. 2019, 14, 566-571. [CrossRef] [PubMed]

48. Yang, C.L.; Creath, R.A.; Magder, L.; Rogers, M.W.; McCombe Waller, S. Impaired posture, movement preparation, and execution during both paretic and nonparetic reaching following stroke. J. Neurophysiol. 2019, 121, 1465-1477. [CrossRef] [PubMed]

49. Liao, C.F.; Liaw, L.J.; Wang, R.Y.; Su, F.C.; Hsu, A.T. Relationship between trunk stability during voluntary limb and trunk movements and clinical measurements of patients with chronic stroke. J. Phys. Ther. Sci. 2015, 27, 2201-2206. [CrossRef] [PubMed]

50. Van Kordelaar, J.; Van Wegen, E.E.H.; Kwakkel, G. Unraveling the interaction between pathological upper limb synergies and compensatory trunk movements during reach-to-grasp after stroke: A cross-sectional study. Exp. Brain Res. 2012, 221, 251-262. [CrossRef] [PubMed]

51. Smania, N.; Gambarin, M.; Tinazzi, M.; Picelli, A.; Fiaschi, A.; Moretto, G.; Bovi, P.; Paolucci, S. Are indexes of arm recovery related to daily life autonomy in patients with stroke? Eur. J. Phys. Rehabil. Med. 2009, 45, 349-354.

52. Kwakkel, G.; Kollen, B.; Lindeman, E. Understanding the pattern of functional recovery after stroke: Facts and theories. Restor. Neurol. Neurosci. 2004, 22, 281-299.

53. Murphy, T.H.; Corbett, D. Plasticity during stroke recovery: From synapse to behaviour. Nat. Rev. Neurosci. 2009, 10, 861-872. [CrossRef] 